\title{
Temporalities and the conservation of cultural relic protection units: legislative, economic and citizen times of the Bugaoli community in globalising Shanghai
}

\author{
Kaiyi Zhu* (D) and Carola M. Hein
}

\begin{abstract}
Since the establishment of treaty ports in the mid-19th century, the urban development of many Chinese cities, and notably of Shanghai, has been heavily influenced by global economic flows and global urban and architectural practices. In Shanghai, extensive lilong neighbourhoods stand as remnants of the treaty port era. Many of these historic districts are in close proximity to rapidly transforming areas of the city, creating civic tension around demolition, conservation and the redevelopment of colonial heritage. Examining the listed Bugaoli community in Shanghai's old French Concession, the heritage strategies applied under the particular Cultural Relics Protection System (CRPS), and the discourse of local residents interviewed in the context of this project, this paper reveals the paradoxes around urban heritage conservation and urban development by considering three different temporalities: legislative time, economic time and citizen time. The paper argues that actors involved in heritage practices should consider both space and time related issues in urban heritage conservation. Historic communities such as Bugaoli experience conflicts between conservation and the demands of everyday life. They underline and require a heritage strategy that acknowledges diverse temporalities and balances legal norms, economic interests and the public's demands.
\end{abstract}

Keywords: Cultural Relics Protection System (CRPS), Bugaoli (Cité Bourgogne), Legislative time, Economic time, Citizen time, Temporalities, Shanghai, Urban heritage conservation

\section{Introduction}

At a time when China and its cities are booming, the question of how to deal with rapid urban growth and the conservation of Chinese urban legacies remains largely unresolved. Long-standing traditions regarding the protection and display of antiquities govern debates about Chinese heritage. The category of 'cultural relic' (wenwu) and a focus on physical protection and restoration may be appropriate for smaller-scale objects, but fails at the scale of buildings and urban areas that have evolved over long periods of time. Urban heritage activities take place within different temporal

\footnotetext{
* Correspondence: K.Zhu-1@tudelft.nl

Faculty of Architecture and the Built Environment, Delft University of

Technology, Julianalaan 134, 2628 BL Delft, Netherlands
}

regimes and are often constrained by the realities of a slowly moving legal system. After the establishment of the People's Republic of China, a few significant prominent historic buildings and sites were recognised as 'cultural relics' under the Cultural Relics Protection System (CRPS, 文物保护制度). Established in 1949 and continually amended by the State Council of China, in 1982 this system was legally promulgated by the Cultural Relics Protection Law of the People's Republic of China (the Law). ${ }^{1}$ In 1989, Shanghai was the first municipality to promote the listing of select 20th century modern architecture as cultural relics, which inspired much

\footnotetext{
${ }^{1}$ On November 19, 1982, the Cultural Relics Protection Law of the People's Republic of China was approved at the 25th Session of the Fifth National People's Congress of the People's Republic of China, and later issued for implementation by the State Council of China.
}

\section{Springer Open}

๑ The Author(s). 2020 Open Access This article is licensed under a Creative Commons Attribution 4.0 International License, which permits use, sharing, adaptation, distribution and reproduction in any medium or format, as long as you give appropriate credit to the original author(s) and the source, provide a link to the Creative Commons licence, and indicate if changes were made. The images or other third party material in this article are included in the article's Creative Commons licence, unless indicated otherwise in a credit line to the material. If material is not included in the article's Creative Commons licence and your intended use is not permitted by statutory regulation or exceeds the permitted use, you will need to obtain permission directly from the copyright holder. To view a copy of this licence, visit http://creativecommons.org/licenses/by/4.0/. 
debate. Particularly controversial was the protection of urban vernacular such as the so-called 'lilong' neighbourhoods, in the old foreign settlements, that were associated with both extreme disrepair and colonialism. For many, lilong communities and the lifestyle exemplify the community characteristics of the Shanghainese. In many ways, their unique infrastructure and lifestyles have not vanished with time but have strengthened. They serve as a marker of Shanghainese identity and history and as a point of contrast with other regions of China. However, residents in heritage areas are often left to fend for themselves, caught between legislative time constraints, economic time pressures and a lifestyle that emphasises community awareness and a collective spirit (Champion 2019). How to conserve and wisely reuse this urban residential heritage that involves multiple actors and different temporalities remains a significant challenge.

Global urban heritage conservation discourse has steadily devoted more concern to time related issues since the 1970s, as conservation is no longer only seen as involving tangible spaces but also about intangible practices formed by time, in history, and dependent on human memories. However, the definition and scope of 'community' heritage have not been well studied. Often, diversity related to histories of colonialism, racialism or terrorism contributes to the difficulty of definition. The nonlinear and unrealistic nature of time, its plurality formed by both simultaneous and parallel temporal experiences and practices involves multiple temporal regimes. There are different perceptions and dimensions of time that exist in a neighbourhood, a city and a region. By attending to this variation, we can enhance people's participation in heritage practice, whether they are local residents, the public or professionals.

Once established, urban areas evolve at different speeds. To better understand and assess the dynamic nature of urban development and the role of temporalities in urban heritage conservation, in 2018 the authors initiated a pilot study to research these issues in the Bugaoli (步高里) community, one of the first listed historic lilong neighbourhoods of Shanghai. Reporting on this pilot study, this paper challenges authorised heritage discourse in the current global conservation circumstances by investigating a controversial historic community which was, contrary to some perceptions, never only a colonial settlement or a community dominated by white elites.

Areas that are officially recognised as heritage sites have little opportunity to transform, even when surrounded by a vibrant economy. Bugaoli is an example of the sometimes stifling effect of urban heritage conservation. This paper first considers contemporary urban conservation and community heritage discourse, and its adaption in scholarship on Shanghai. It then investigates the concept of temporality and its significance for understanding urban heritage conservation; it explains the methodology used in the site survey and reasons for selecting Bugaoli. The paper identifies three basic temporalities: legislative time, economic time and citizen time. The scope of temporal regimes can extend to include media time, technological time or cultural time, depending on the influential time dimensions that are important in a particular context. Explaining the meaning of each temporal regime, on the basis of a questionnaire, multiple interviews, and site survey investigation in Bugaoli and the city centre of Shanghai, the paper then examines the challenges of urban heritage conservation at the intersection of the three temporalities. It argues for the need to consider the effect of authorised legislation on people's everyday lives, in order to develop community-based and flexible heritage strategies.

\section{Urban conservation discourse}

Existing urban conservation discourse is characterised by a focus on space. Since the 1970s, natural resource shortages and the ecological damage caused by industrialisation and massive demolition have broadened the horizon of heritage practitioners (Vecco 2010; Ahmad 2006; Harvey 2001). They have become more inclined to see not only single historic buildings but also historic sites and landscapes (Jokilehto 2007; ICOMOS 1987; UNESCO 1976). Many cities can no longer grow outward, and stakeholders need to reuse existing spaces, raising questions about urban heritage conservation. Urban development and conservation interact and promote a process of culture assessment and critical thinking regarding urban heritage (Martokusumo 2002). Kohl et al. (2016) argue that the underlying cause of the current difficulties in practice lies in the discipline itself; although they acknowledge the rising importance of a continuous heritage plan for future decision-making. Their book The Future Has Other Plans does not avoid the tendency to see heritage management and practice from a primarily spatial perspective, ignoring the role of local communities. Regarding urban heritage as a product of culture, scholarly discussions and debates mainly focus on heritage values and definitions and promote various spatial strategies that benefit the tourism industry and gentrifying neighbourhoods. ${ }^{2}$

The creation of heritage is a dynamic phenomenon. Lowenthal and Binney (1981) argues that heritage protection results from a series of sociocultural processes. Following Lowenthal's speculation and bewilderment in his book titled The Past is a Foreign Country (1985),

\footnotetext{
${ }^{2}$ Many recent publications focus on the tourism industry and architectural adaptions, such as the work of Kaminski et al. (2017) Contemporary Issues in Cultural Heritage Tourism and Cheryl Hargrove's (2017) book Cultural Heritage Tourism: Five Steps for Success and Sustainability.
} 
contemporary scholarship has investigated the formation of cultural history based on both individual and common memories and their life experiences. Exploring various themes within memory making, Smith (2006) further redefines heritage in her book Uses of Heritage by regarding it as a 'process' rather than a 'thing'. Scholars also argue that the term 'community', not clearly defined and understood, is misused in discussions of urban heritage conservation (Waterton and Smith 2010; Greer et al. 2002). By analysing the privileged white middle classes and the lives of members of other ethnic groups in Australia, Waterton and Smith (2010) also reveal the conflicts between the formalised community identity of Western Authorised Heritage Discourse (AHD) and everyday life in an ever-changing society. The conservation of historic urban communities cannot avoid heritagisation led by capitalism and authority, ignoring the significance of time, collective memories and life experiences in urban space. ${ }^{3}$

Urban conservation overlooks time as an issue, detouring around it or attending to its connection with only the past but not the future. In historic communities, as long-term residents are getting older, those sites will inevitably face situations such as housing vacancy, population decline, a loss of vitality and gentrification. In a growing metropolitan and cosmopolitan area like Shanghai, urban areas that were built by colonial actors, such as the lilong settlements, are caught between the desire to preserve traditional neighbourhoods, nationalist sentiments and the pressures of real estate development and the benefits of rapid economic growth. In its historic centre, Shanghai is experiencing conflicts between urbanisation and heritage conservation, poverty and gentrification, community awareness and dynamic diversity.

Heritage discourse has become global in a way that excludes local perspectives. Studies of urban heritage in Shanghai have not taken into consideration the concept of time and relevant theories, even though scholars like Bonfiglioli and Ma (2010) have started to embed time in the study of urban planning. Focusing on a chronological study of the evolution of heritage protection, ideological progress and its morphological changes in China (Chang 2019; Lu and Li 2019), Chinese scholars use case studies to demonstrate different phenomenon or reveal problems in urban heritage practices; existing papers neither provide a distinctive Chinese perspective to enrich the understanding of urban heritage conservation for other nations nor challenge the contemporary

\footnotetext{
${ }^{3}$ The concept of heritagisation is persistent. Rodney Harrison (2013) defines 'heritagisation' as a process through which objects, places, traditions or behaviour can be turned into heritage in his paper "Forgetting to Remember, Remembering to Forget: Late Modern Heritage Practices, Sustainability and the "Crisis" of Accumulation of the Past".
}

heritage discourse that is dominated and controlled by white elites. Shanghai's lilong neighbourhoods have complicated reputations: as the remains of colonialism, as refugee ghettoes, as welfare-oriented public housing, and as cultural heritage. Neighbourhood residents have witnessed a sudden rise in the popularity of heritage discourse in many quarters ( $\mathrm{Lu}$ and $\mathrm{Li}$ 2019). In this respect, an in-depth study of historic communities and local participators can enhance the engagement of local perspective in the global discourse. To encourage a focus on the contemporary urban agenda of Shanghai, decision-makers may want to notice the diverse local heritage narratives formed by power, the society and individuals in particular communities.

\section{Temporalities}

Concern for intangible values of urban heritage helps shift attention from space to time. The concept of temporality becomes important in urban heritage conservation as multiple actors participate in a single case and take actions based on their own interests. Human society does not follow absolute universal time, which is usually abstract, transcendent and homogenous (Benjamin and Eiland 2003). Each city has its own rhythm of urban development (Henckel and Susanne 2013). The unequal distribution of economic, political, cultural and subjective structures in a city produces its own temporalities (Sassen 2000). In big cities, there are numerous temporalities shaped by political, legislative, economic, material geographic and technical forces that cross multiple dimensions and disciplines in the dynamic processes of human society (West-Pavlov 2012).

In the past, the needs of multiple temporalities have led to the spatial expansion in cities. With excessive development of urban land, problems and pressure of imbalances in urban areas open space for new construction is largely absent, and development pressures focus on existing sites. Understanding time helps to recognise the interdependence of temporary occurrences and eternal time. Once established, urban areas evolve at different speeds. In the context of urban heritage conservation, phases of economic development require demolition, reconstruction and reuse as a result of social conditions as well as changing economic and political circumstances. A variety of urban players are in constant dialogue and often struggle over spaces in the city and opportunities for development. Urban temporalities, according to the participating actors, may include various temporal regimes formulated by national and local regulations, economic activities, common culture and history, and media communication or individual memories.

The three most influential temporal regimes in Bugaoli are the CRPS legislation, the economic goal of creating a 


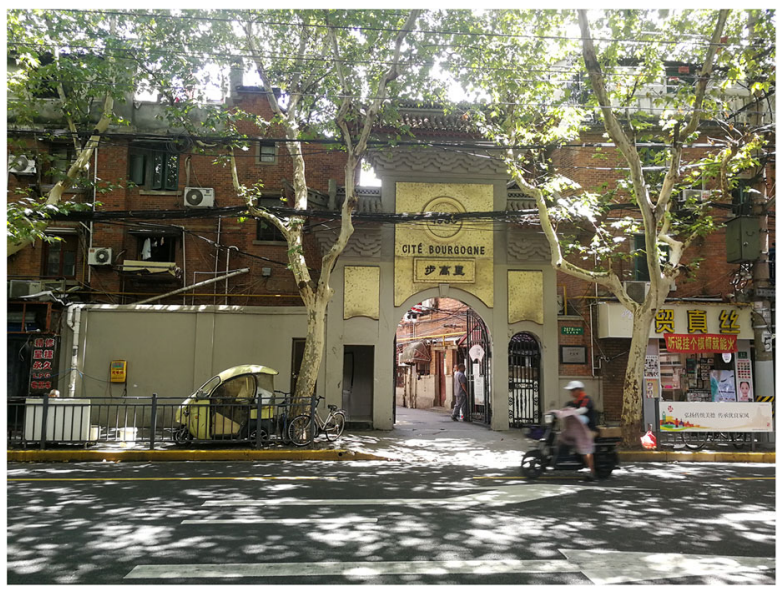

Fig. 1 Facing the South Shaanxi Road, the French name 'Cité Bourgogne' and the Chinese name '步高里' were carved on the archway of the main entrance (Source: Kaiyi Zhu, 2018)

tourism brand, and residents' activities. Legislative time defines the effort-consuming process of promulgation a statutory law. Compared with dynamic economic trends, legislative time develops with decision-makers' cautions and deliberation. As we will argue, legislators often cannot keep up with the rapidly changing urban environment of the 21st century. In this paper, 'citizen time' refers to local residents who are involved in any urban conservation practice; this definition emphasises both rights and obligations of local inhabitants in their community. The temporal regime of citizens involves subtle points of focus, a community's internal processes and changes. Legislative time, economic time and citizen time vary from state and city to neighbourhood, from collective to individual, and from persistent discipline to dynamic performance.

\section{Methodology and site}

In the 21st century, various groups in Shanghai have been involved consciously or unconsciously in urban heritage conservation. Lilong housing presents an opportunity to explore the tangible and intangible aspects of different temporal regimes. In order to understand different positions of various participants and their group characteristics in urban conservation, we conducted a questionnaire-based survey in 2018 with the intention of gathering information about the perspectives of the following: governmental personnel (GVP), heritage conservation practitioner (HCP), architecture or urban planning practitioner (AUP), investment developer (IVD), resident in the historic neighbourhood (RHN), merchant or retailer (MCR), the public (TPB) and member of the community or public organisation (CPO). In order to understand the opinions of members of the different targeted groups, we also conducted 20 one-to-one or one-to-many interviews in site after collecting more than 300 questionnaires. One shortcoming of the interview methodology may be that more participants were long-time residents and that it lacks some insight from newcomers, including both the young migrant workers and tourists for short-stay in renovated apartments. Discourse analysis reveals that most interviewees considered famous tourist sites Xintiandi, Tianzifang, Sinan Road or the old Columbia Country Club to be social hot spots. Study participants mentioned these sites as inspiring examples of 'urban conservation', ignoring illegal or inappropriate behaviours that take place at those sites and also ignoring the significance of the sites to local residents as cultural heritage. The listed Bugaoli community has not become a tourist site and has been maintained under the guidance of the CRPS. It can, therefore, be used as an example to study the issues that are often overlooked by the public. However, in the published literature, scholars have not explored the unique aspects of the CRPS in China, the position and role of local residents, and their interactions with municipal construction and economy. ${ }^{4}$ In this paper, we shift the analytical viewpoint from spatial analysis to the exploration of collaboration and conflicts of different temporal regimes, revealing the temporalities of urban heritage conservation in big cities.

The name Bugaoli is derived from the location's original French name 'Cité Bourgogne', with similar pronunciation and meaning 'a step up' in Chinese (Fig. 1). In 1930, during the French Concession period, the Bugaoli neighbourhood was at the junction of the old Avenue du Roi Albert and Route J. Frelupt (Fig. 2). ${ }^{5}$ It occupied a large urban space and consisted of 79 units designed with a typical lilong urban texture, featuring hierarchically organised alleyways (Fig. 3). It integrated traditional Chinese archways (Fig. 4), red bricks, structural timbers and European-style terrace buildings (Fig. 5), resulting in a unique combination of Chinese and Western features. Initially, foreign-built housing for the middle and upper classes, with the increased industrialisation of Shanghai after the establishment of the PRC, Bugaoli became a working-class area.

Legislatively, the designation of Bugaoli as protected marked a shifting point in urban conservation, a starting point for the protection of other residential communities.

\footnotetext{
${ }^{4}$ In scholarship, Zhu and Zhu (2012) anthropologically record details of indigenous inhabitants' seventy-years lives, based on an analytical study of its architectural and urban history; Zhong and Chen (2017) investigate three stages of urban transformation beginning in 1990 by comparing cases Xintiandi, Tianzifang and Bugaoli, which are also classified and entitled as specific heritage practice modes by Qing Chang (2009).

${ }^{5}$ After the establishment of the People's Republic of China, street names were changed by a new naming system. Thus, the old Avenue du Roi Alber is named as South Shannxi Road and the old Route J. Frelupt is the present West Jianguo Road.
} 


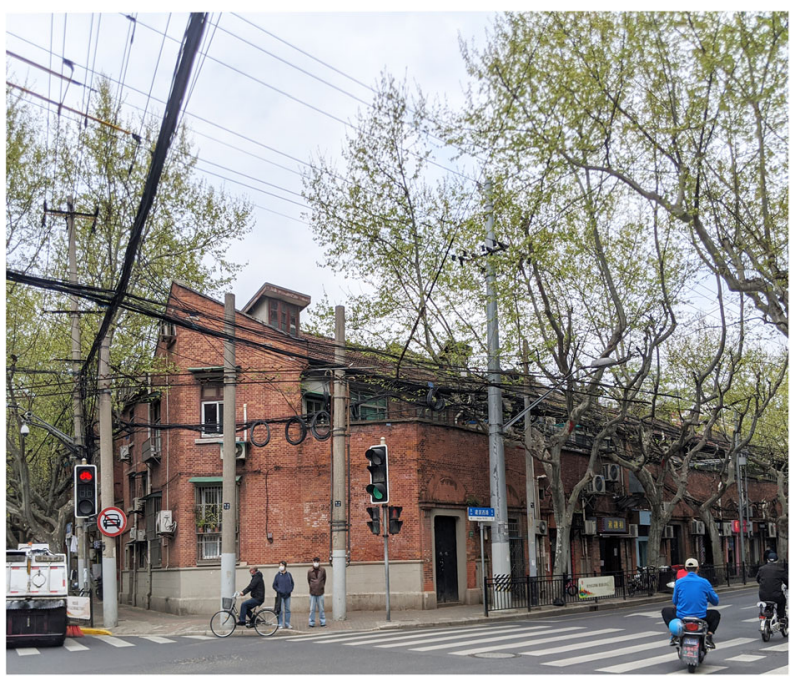

Fig. 2 The view of Bugaoli Neigbourhood from the intersection of the South Shaanxi Road (Avenue du Roi Albert) and the West Jianguo Road (Route J. Frelupt) (Source: Kaiyi Zhu, 2018)

In contemporary Chinese cities, it was not until 1989 that modern architecture was first approved within the scope of cultural relics under the CRPS and Bugaoli was designated as a Cultural Relics Protection Unit (CRPU) on this list (Table 1). The CRPS was established in 1949 and has been continually amended by the State Council of China. It became legally effective with the promulgation of the Cultural Relics Protection Law of the People's Republic of China (the Law) in 1982. On the basis of a long-standing tradition, this legal framework is designed to protect and display antiquities. ${ }^{6}$ Lu and $\mathrm{Li} 2019$ has described the difficulty for a concession-period legacy to get national recognition given its controversial identity related to colonialism. In order to maximise the protection of local urban heritage, in the 1980s, Shanghai's local officers and professionals made great efforts to assert the significance of its modern legacies. Currently, two parallel departments share responsibility for managing the city's urban and architectural heritage. The Shanghai Municipal Administration of Culture Heritage (上海市文物局) manages protection units beneath the municipal level under the guidance of the CRPS. The Shanghai Planning and Natural Resources Bureau (上海市规划和自然资源局) monitors a broader range of historic buildings and areas by issuing the local Regulations of Shanghai Municipality on the Protection of the Areas with Historical Cultural Features and the Excellent Historical Buildings (上海

\footnotetext{
${ }^{6}$ The term 'cultural relic' appeared early in the Chinese history (1050$771 \mathrm{BC})$, in the Zhou Dynasty, and is still in use today.

${ }^{7}$ The sector Shanghai Municipal Administration of Culture Heritage (上海市文物局) is one part of and under the guidance and management of the Shanghai Municipal Administration of Culture and Tourism (上海市文化旅游局).
}

市历史文化风貌区和优秀历史建筑保护条例) and it has the authority to list Shanghai Excellent Historical Buildings (上海市优秀历史建筑). ${ }^{7}$ Bugaoli has been designated both as a CRPU and as a Shanghai Excellent Historical Building. Although this designation has protected Bugaoli from demolition or radical redevelopment, it maintains the neighbourhood in frozen time, watching a trend of losing the community's vitality and diversity.

In 1988, the municipality of Shanghai promulgated a land leasing policy that gives the local government the right to make a profit by leasing land (Wu 2000; Yang and Chang 2007). Under this policy, lilong neighbourhoods that were nationalised after the establishment of the PRC have entered into a commercial market for historic housing. The favourable real estate development conditions and commodity economy led by neoliberal capitalism forced the lilong properties to function in a capitalised environment (Butler 2007; Harvey 2005). Between 1993 and 1999, as a result of radical redevelopment, the number of well-conserved lilong housing units dropped dramatically from 3,754 to 952 (Zhang 2006; Shen 1993). ${ }^{8}$

Residentially, the internal population structure of Bugaoli has reflected the changes of Shanghai as a whole. According to demographic sources of Luwan District municipal office, around 1949, there were about 233 households and 1410 permanent residents (Zhu and Zhu 2012, 45). ${ }^{9}$ As of January 2017, there were 387 households and 587 permanent residents, although 957 residents were registered in the Bugaoli neighbourhood. ${ }^{10}$ In 1949, the population consisted of white-collar workers, teachers and intellectuals. Only one family was working class. In 2017, the population of Bugaoli was mainly composed of retired seniors and low-income migrant labourers. The seniors account for $59.6 \%$ of the permanent residents. ${ }^{11}$ The declining number of permanent residents did not bring about more spacious living conditions, and the increased number of households exposes the problem of social polarisation in one community area.

\footnotetext{
${ }^{8}$ The number shown in this paper includes the quantity of three types of lilong housing, the first and second stairs of old lilong houses, and the new-styled lilong house.

${ }^{9}$ The term 'permanent residents' in this paper indicates the residents who usually live in Bugaoli daily for a certain period with or without holding census register

${ }^{10}$ The term 'registered residents' here stands for those people who hold the census register of Bugaoli and they can be permanent residents who usually live in this neighbourhood or the ones who can rent out separate rooms to others.

${ }^{11}$ In their paper "Economic Research on Conservation and Regeneration of Bugaoli", authors Yingying Qian and Yanwen Huang provided the statistics found in 2017. Available online: https://www. zhazhi.com/lunwen/jjkx/jjxlw/151741.html (accessed on 03 August 2018).
} 


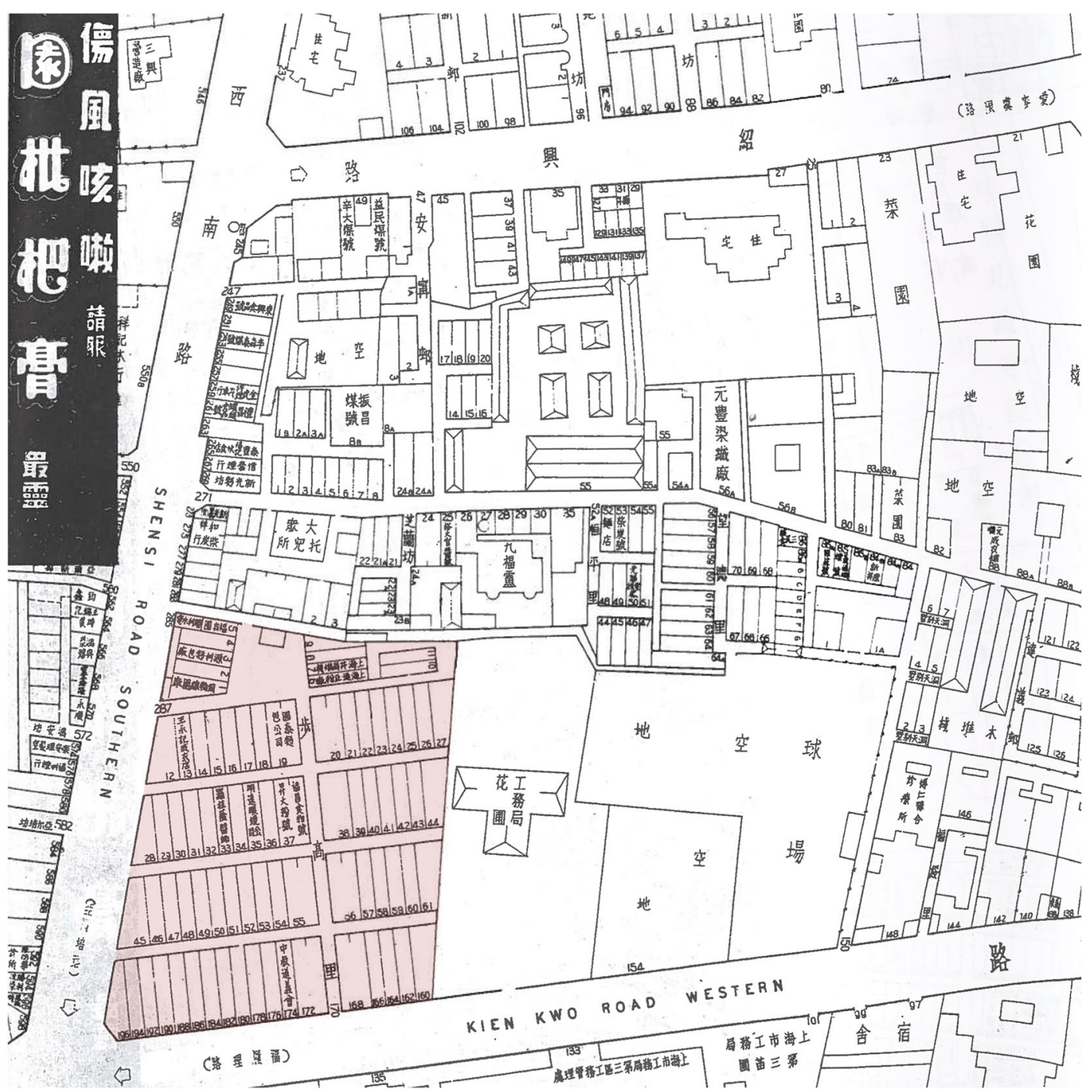

Fig. 3 This historical map shows that compared with its surroundings, Bugaoli involves a large scale of building with highly organised urban texture (Source: Cheng and Wu 2016)

Some families cope with crowded living spaces, while others benefit from small-scale gentrification and liberal economic activities.

As a case study, Bugaoli is significant for four reasons:

1. It contains an active community in which we can meet many local residents and observe daily activities within Bugaoli in an urban transition period when the development priority shifted from space to time.

2. Bugaoli's diversity has led to a collision of ideas. Conflicts include those of residents with the increasingly globalised living environment and urban landscape in Shanghai but also internal conflicts among residents.

3. Because Bugaoli is listed as a Cultural Relic Protection Unit (CRPU) and a Shanghai Excellent
Historical Building, a dramatic opposition exists between the designated image and reality.

4. Bugaoli is located in one of the most popular areas in Shanghai and is surrounded by rapid gentrification and redevelopment.

Discourse analysis has been used to examine the questionnaire responses and interviews. In the 2018 site survey, local residents' attitudes and discourses differed from each other according to their growing experience. For the purposes of the study, we divided residents of Bugaoli into three groups: (1) residents who had moved

\footnotetext{
${ }^{12}$ Residents of Bugaoli whether they are registered or not have no ownership of the houses in this community and only have the right to use them and pay low rental fee to the property management department under the local government's jurisdiction or pay market rent to the second (third) residency owners.
} 


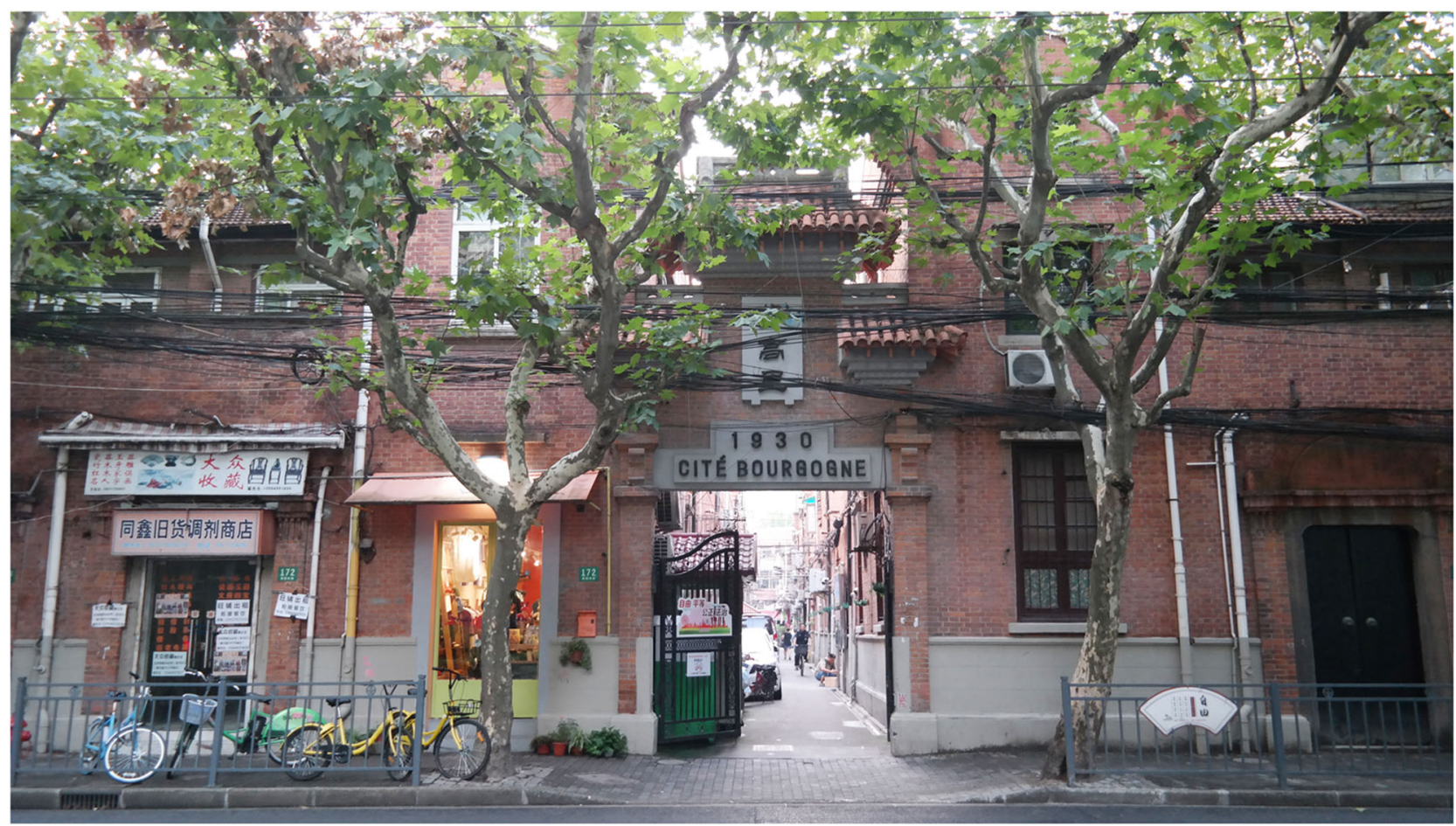

Fig. 4 The Chinese-looking archway of the Bugaoli neighbourhood, being an entrance gate of this community (Source: Kaiyi Zhu, 2018)

to Bugaoli before 1949 or lived in this neighbourhood since birth; (2) residents who moved to Bugaoli between the 1950s and 1970s and enjoyed social welfare housing sharing policy during Shanghai's industrial development period; and (3) newcomers, in particular young migrant workers who moved in after the 1980s when Shanghai entered a market economy period. ${ }^{12}$ Other historic lilong neighbourhoods in Shanghai experience similarly complicated situation. Bugaoli has non-negligible and definite representativeness, challenging assumptions within the dominant mode of urban heritage conservation.

\section{Legislative time: national policies and the Cultural Relics Protection System (CRPS)}

Promulgating laws and public regulations takes time, and their implementation is often slow. Once put into

\footnotetext{
${ }^{13}$ The Office of Shanghai Chronicles records that on January 14, 1989, the government of Shanghai organised a meeting to assess and appraise the values of modern buildings, and current heritage and architecture related professionals, such as the Zhi Chen, Jingxiang Wu, Jizhong Feng, Xiaowei Luo and Dehua Li were included in this assessment committee and selected 59 outstanding sites for nomination. The local government also submitted the nominated 59 modern heritage to the current Ministry of Construction and Ministry of Culture for the selection of the national key cultural relics protection units. On September 25, 1989, the Shanghai municipal government also approved the 59 outstanding modern architecture as cultural relics protection units of Shanghai. Available online:http:// shtong.gov.cn/newsite/node2/node2245/node4467/node20561/node205 71/node63799/userobject1ai16103.html (accessed on 20 April 2019).
}

effect, a legislative framework may have an impact over decades or even centuries. Legislation pertaining to heritage conservation is not always in line with short-time economic development goals nor with the everyday temporality experienced by the residents of impacted neighbourhoods. Bugaoli's status as a listed cultural relic has hindered its transformation in terms of modern residential living standards and commercial redevelopment. For China's urban areas, the strategies and approaches of heritage conservation have yet to fully express and convey the inherent cultural and social values of each historic community (Canziani 2008). Three important points can be made about Bugaoli's status as a cultural relic frozen in time. First, the Shanghai municipality took a leadership role in conserving modern architecture and neighbourhoods like Bugaoli that obviously reflected colonial influence. Second, the focus on achieving tangible conservation objectives was disconnected from the desire for intangible conservation, which excluded the possibility of residents' participation and created an incoherent protection strategy. Third, as they go about

\footnotetext{
${ }^{14}$ Most of the historical buildings which were built before 1949 were rearranged and gradually classified as government-owned public properties (直管公房) after the establishment of PRC; Bugaoli is currently a government-own site.

${ }^{15}$ The Cultural Relics Protection Law of the People's Republic of China was officially approved and published in 1982. It was revised four times in the past. The current executive version was revised in 2015 and approved in 2017.
} 


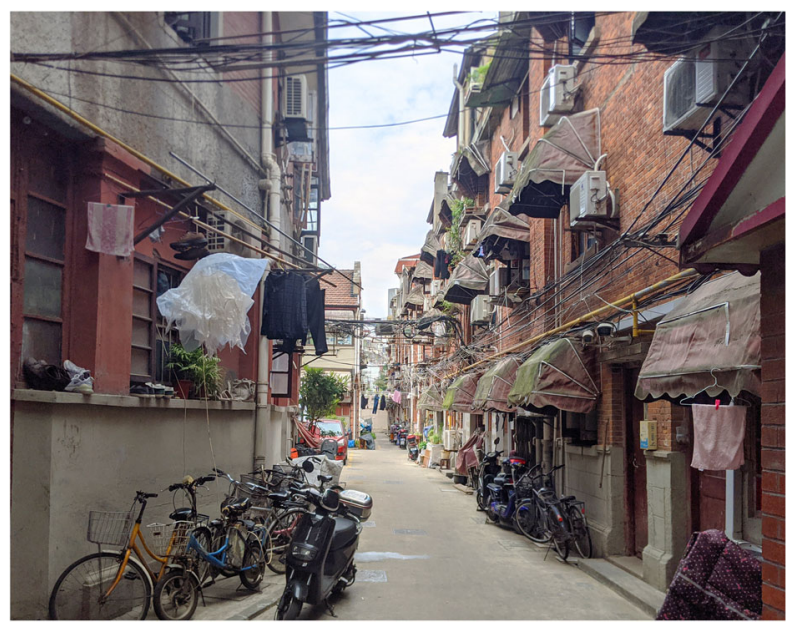

Fig. 5 The organized terraced buildings in Bugaoli, constructed with red bricks and timber window frames and door panels on the architectural façades (Source: Kaiyi Zhu, 2018)

their daily lives, community members are influenced by legal interventions, and they recognise the significance of heritage conservation principles and approaches.

Long influenced by international exchanges, both scholars and local government officials in Shanghai have been aware of the global discourse on heritage conservation. In line with international trends that emerged in the 1970s, they have demonstrated increasing concern for the conservation of 'community' and larger sites (Waterton and Smith 2010). In Shanghai, this movement in heritage studies has affected the formulation of urban regulation and policy. In 1989, the Shanghai Construction Committee (上海市建设委员会) and Shanghai Cultural Relics Management Committee (上海市文物管理委员) nominated 59 outstanding modern buildings as cultural relics of national importance to the central government. ${ }^{13}$ This action made Shanghai the first city in China to treat modern buildings built during the treaty period as a separate category in the heritage framework. Debates about such controversial heritage will continue, and it is irresponsible to conduct urban transformation without facing Shanghai's history of colonialism-a history which has been intentionally marginalised by Shanghai's local scholars. The listed status had admittedly prevented the destruction of Bugaoli at a time when other such sites were destroyed, although little has been done to protect the historical architecture and community lifestyle.

\footnotetext{
${ }^{16}$ 'Do not act' in this paper means that the residents in Bugaoli community can either make no contribution to architectural restoration or conservation approaches or make effort to provide ideas for the sustainable development of this area when living in the listed historic dwellings. This situation can also be regarded as 'take no responsibility' for this community.

${ }^{17}$ This interview was conducted in 2018 by Kaiyi Zhu in the office of the Bugaoli Neighbourhood Committee.
}

In 1989, when Bugaoli and other modern buildings were nominated as CRPUs for the first time, vernacular architecture such as lilong housing started to gain attention within China's heritage discourse. The official title of 'cultural relic' could not, however, provide a solid protection mechanism for these marginalised areas, that cannot stand out from those magnificent buildings or famous legacies and monuments. The Standing Committee of the National People's Congress issued and amended the Law several times, but the expectations and imagination of the authority did not address the difficulties in practice inherent in the protection of largescale government-owned properties. ${ }^{14}$ This strategic neglect placed the burden of the conservation of Bugaoli and other similar historic urban communities on the residents, as demonstrated clearly in Article 26 of the Law:

The principle of keeping the immovable cultural relics in their original state shall be adhered to in their use, and the users shall be responsible for the safety of the structures and the cultural relics attached to them, see to it that the immovable cultural relics are not damaged, rebuilt or dismantled and that no additional structures are built on the site. (State Council 2017) ${ }^{15}$

In practice, the Shanghai municipality has taken over many heritage protection tasks in line with the cultural image created for Shanghai. This initiative by local government is tightly related to the municipality's construction aims, but it is inconsistent with the legislation and with Article 26 in the context of cultural relics protection. In Bugaoli, the local residents accepted and enjoyed the heritage privilege granted by the government's 'do not act' commandment without understanding the degree to which their everyday activities would impact the conservation of the neighbourhood. ${ }^{16}$ The absence of protection activities from local residents in Bugaoli counteracts the conservation of the intangible and immaterial qualities of the community. The listed status of the site did not emphasise the significance of community conservation to the residents, nor did it take into account the responsibility for heritage conservation from below.

Laws have an impact on materiality. Although selected for their outstanding historic qualities, listed neighbourhoods such as Bugaoli are inevitably deteriorating. Their listed status pushes stakeholders to take a heritage approach in line with domestic legal standards and international conservation principles. Ms Wang, the party branch secretary of the Bugaoli Neighbourhood Committee (BNC), expressed in a 2018 interview that 'We are going to restore all the front gates along the streets with black colour and timber, the same as their original design. ${ }^{, 17}$ In the past, such stakeholders did not become involved in 
Table 1 The seven residential areas or buildings were all listed in 1989. Among these nominations, Shangxianfang has the longest history of existing, Bugaoli follows close behind

\begin{tabular}{lllll}
\hline Batch & Time & Name & Construction Time & District \\
\hline 5 & 1989 & Shangxianfang & $1921^{\text {a }}$ & Huangpu \\
5 & 1989 & Bugaoli (Cité Bourgogne) & 1930 & Huangpu \\
5 & 1989 & Cosmopolitan Apartments & 1934 & Jing'an \\
5 & 1989 & Bubbling Well Lane & 1936 & Jing'an \\
5 & 1989 & Yuhua New Village & 1941 & Jing'an \\
5 & 1989 & Xinkang Garden & 1933 & Xuhui \\
5 & 1989 & Lane 115, Tai'an Road & 1948 & Changning \\
\hline
\end{tabular}

${ }^{a}$ Based on the information from the Local Records Office of Shanghai, another view claims that Shangxianfang was built in 1924 instead of 1921 . Available online: http://www.shtong.gov.cn/Newsite/node2/node4/node2249/node85092/node85129/node85608/node85612/userobject1ai125860.html (accessed on 20 April 2019).

conservation practice. If there were no conscious heritage restoration actions in the listed Bugaoli from below, the other unlisted historic sites might deteriorate more quickly. Considering Bugaoli's urban and architectural character, Ms Wang's words may indicate a change in the attitude of community representatives, and they suggest a shift in legislative time in Bugaoli. As the BNC theoretically represents the interests of the local residents, this heritage approach of repairing front gates involved the participation of local inhabitants and was approved by resident commissioners from Bugaoli. Legislative time and citizen time have progressively coincided in Bugaoli. After Bugaoli's designation in 1989, there was no obvious tangible or intangible improvement taking place in this community. Restoration or renovation by the community within the context of heritage may now go forward. Nevertheless, it is too early to predict any positive results in Bugaoli's neighbourhood movement for urban conservation. There is a dilemma between reality and legal intervention: the authoritativeness of discourse in academia and government dominates in practice, while there are vague definitions of many heritage-related terms in the Law and regulations in China's legislative framework. In this respect, BNC cannot undo the influence of multiple and vague interpretations of urban conservation caused by the general heritage environment in Shanghai. Legislative time in Bugaoli is inevitably entangled with other temporal regimes but holds the most powerful way.

The Cultural Relics Protection Law of the People's Republic of China creates benefits and privileges for Bugaoli-such as government input for its physical improvement and protection from being damaged but does not address the loss of community focus and collective memory, which were once community strengths. However, in the legislative system of cultural relics, content referring to 'the users', meaning local residents or citizens in general, did not help to clarify the difference between these two temporal regimes or to reduce the gap between them. From the perspective of urban heritage conservation, the struggling reality in citizen time and the ideological rules in legislative time reflect the essential conflicts inherent in community conservation. The longer-term legislative regime in Bugaoli as well as in other historic neighbourhoods is the foundation for the short-term economic time and residents' ever-changing activities in citizen time. The focus of urban conservation is to ensure that heritage continues to exist. The framework of legislative time in Bugaoli provides the baseline for actions within the temporal regimes of citizen initiatives and economic development. Their alignment ultimately protects Bugaoli's future.

\section{Economic time: urban transformation and touristic heritage approaches in Shanghai}

The economic development of Shanghai focuses on collective identity in line with the municipal government's recent desire to be a global city. The economic benefits of conservation play out on a larger scale than the Bugaoli community. Economic time is compressed to the time a developer needs to make a profit on their investment. To realise that profit, decisive decisionmaking on projects and quick transformations are necessary. The pursuit of economic benefits is expressed in booming urban development, including high-rise construction and lighthouse projects generated by globalisation and cross-national trade in the areas surrounding the Bugaoli community, which stands in the core business district. The Shanghai municipality's economic goals are also reflected in limited, technical one-time interventions and investment in Bugaoli. As a listed cultural relic owned by the government, Bugaoli is one of Shanghai's most significant public legacies and an emblem of the old city centre in the former French

\footnotetext{
${ }^{18}$ Zhong, Xiaohua, and Xiangming Chen. "Demolition, Rehabilitation, and Conservation: Heritage in Shanghai's Urban Regeneration, 19902015." Journal of Architecture and Urbanism 41, no. 2 (2017): 82-91. In this paper, authors Zhong and Chen argue that to conserve the historic lilong houses is to distinguish the local identity of Shanghai.
} 


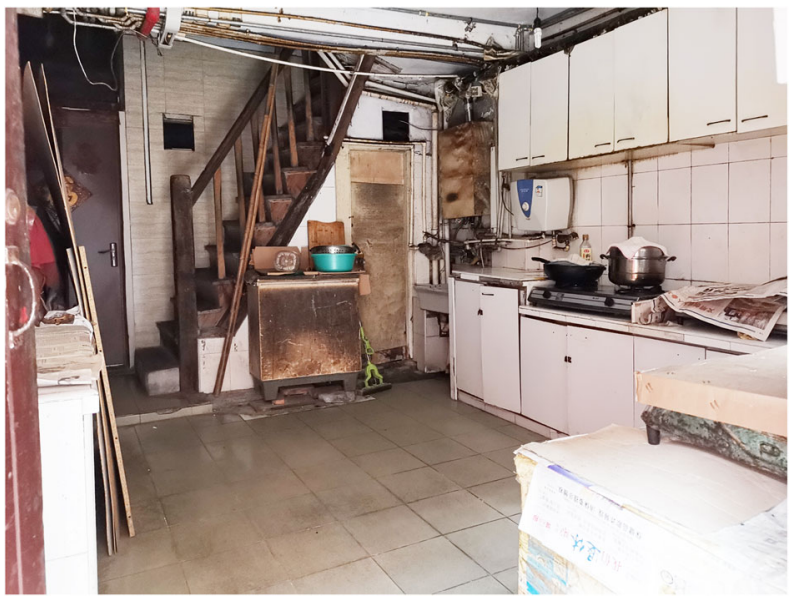

Fig. 6 The kitchen of No. 35, Lane 287, South Shaanxi Road in Bugaoli. After more than 10 years, the white cabinets and consoles, which were equipped in 2007, are still in a relative modern status, compared with the original timber staircases in the room (Source: Kaiyi Zhu, 2018)

Concession. Its unique value is clear in terms of the city's long term economic and planning strategy. The city wants to freeze the neighbourhood's appearance for the benefit of the city's tourist industry. It aims to guarantee that the neighbourhood supports the city's economic goals, most notably through tourism. Second, the government of Shanghai also wants to make sure that the neighbourhood conforms to contemporary safety and security standards. Third, personal activities in Bugaoli stimulated economic activity, increasing its vitality. A few Bugaoli residents purchased new properties in recent decades, moved out and renovated their former living spaces so they could participate in the sharing economy by renting apartments through Airbnb or other online platforms.

Two major comprehensive improvement projects conducted by the municipality and district government agencies had an impact on Bugaoli. For the 2010 Shanghai Expo, a considerable number of historic lilong neighbourhoods were developed as a tourist attraction. With authentic architectural features and a community that has survived since the 1930s, Bugaoli was promoted as an example of the Expo slogan 'better city better life'. Bugaoli residents' needs and interests are not aligned with those of the local municipality's strategy of utilising historic sites for city branding and tourism. ${ }^{18}$ Catching up with Shanghai's economic time meant that Bugaoli had to be upgraded to guarantee safety and security. The 2010 Shanghai Expo provided an opportunity for such an upgrade. In Bugaoli, the improvement focused on six aspects and started in 2007 (Zhu and Zhu 2012). Local

\footnotetext{
${ }^{19}$ This interview was conducted in 2018 by Kaiyi Zhu in Bugaoli community.
}

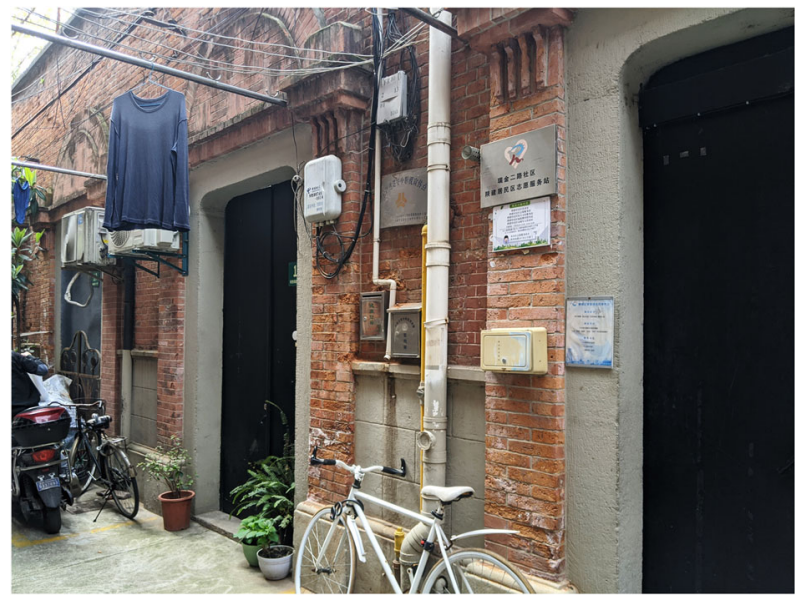

Fig. 7 There are newly added elements on the façades, such as equipment for fire safety and the white sewage outlets (Source: Kaiyi Zhu, 2018)

government took over responsibility from the actual 'users' in 'Toilet Project' and 'Bright Project'. To avoid property ownership and rights disputes that might have resulted from changes in the building layout or land rearrangements, the 'Toilet Project' aimed at 'major repair'. In each single lilong apartment, construction permits were only approved for the household heads from each family. This action minimised conflicts between multiple families occupying a single unit. The goal was to improve the quality of residents' living conditions and to repair old facilities both inside and outside, upgrading kitchen equipment and consoles (Fig. 6), re-laying pipelines for water and gas, and installing fire sprinklers and sewage outlets (Fig. 7). Another city-wide intervention, the 'Bright Project' was part of Shanghai's municipal engineering initiatives and also affected Bugaoli. From 2014 to 2017, this three-year project involved a large number of old residential areas. It benefited more than 6,500 communities and 3 million families in Shanghai. The 'Bright Project' came to Bugaoli in 2016 and improved the capacity configuration standard of energy meters, eliminating safety hazards. It also improved sanitary conditions. Projects in Bugaoli's economic time led by the local municipality focused on installing kitchen and toilet facilities responding to immediate needs in the historic neighbourhoods.

These two government-led projects were aimed to improve people's life quality while respecting the legal mechanisms for facility upgrades. More than 10 years later, the contradictions impacting Bugaoli have become glaring and reveal paradoxes of temporality between decision-makers and everyday users. For example, one elderly person reported that limited by my narrow living space, the installed toilet closet is next to my dining table, and I cannot use that in such a smelly 


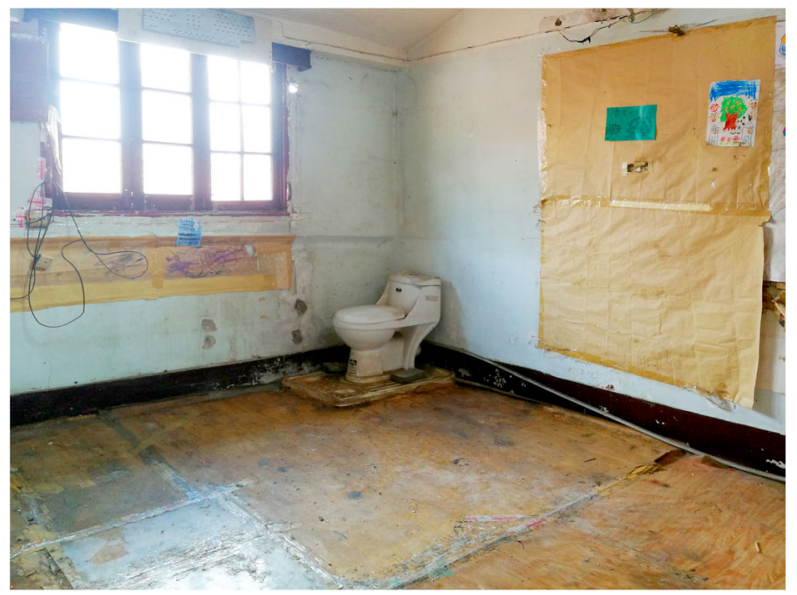

Fig. 8 It is impossible to distinguish between dirty areas and clean areas in one living space. In general, the average living space for each family is nine square meters (Source: Kaiyi Zhu, 2018)

environment (Fig. 8)' ${ }^{19}$ Although local inhabitants were the most influential actor in this lilong neighbourhood, the population has limited decisive role in these projects other than signing consent forms, trapped as they are in citizen time. The residents suffered the consequences of the intervention, even while the local government used the project as an example of their effectiveness. Nevertheless, the local government of Shanghai should not be entirely blamed by either the local residents or scholars for inaction, since the government not only took responsibility but also paid for the renovations, which could not have been afforded by most community members. In Bugaoli, everyday users incurred no financial responsibility with the 'Bright Project', while in the 'Toilet Project' every household provided $100 \mathrm{CNY}$ of the 2,000 $\mathrm{CNY}$ cost. Nonetheless, the population was rarely empowered to make decisions or to propose their own ideas. In general, in the lilong neighbourhoods, the cost for urban heritage renovation and conservation is far beyond the scope of funding that the local government can provide. Whether it is the cultural identity that the Shanghai municipality is dedicated to creating or the low rental prices that the original residents and their later generations cannot abnegate, both the government's and local residents' intention to seek financial benefits are the same. The difference is that the Shanghai municipality pursues economic benefits on a larger scale through tourism, while local residents in historic sites care more about their personal interests. The detachment of economic time and citizen time could not

\footnotetext{
${ }^{20}$ In Matthew Williams' and Non Arkaraprasertkul's (2017) paper "Mobility in a Global City: Making Sense of Shanghai's Growing Automobile-Dominated Transport Culture", they demonstrate that a certain group of lilong residents and prefer to renovate their living places, and turn them into exquisite short-term rental apartments.
}

work for Bugaoli's healthy and sustainable transformation under urban conservation, regardless of its form or property, when long-term residents and their descendants are gradually disappearing from these historic communities.

Located in the most prosperous area of Shanghai, Bugaoli is also a promising place for small-scale businesses. The 2010 Shanghai Expo accelerated efforts to beautify and to promote a capitalised market and globalised urban landscape. Following the rise of trendy fashion boutiques and hotspots in the adjacent Middle Huaihai Road, a number of small upscale stores opened on South Shaanxi Road catering to the petite bourgeoisie and wealthy, including young people and foreign visitors. With the steady increase in Shanghai's international fame and a marketing image enhanced by local governmental policies, increasing numbers of tourists prefer to stay in renovated lilong apartments than monotonous chain hotels. This is facilitated by the internet and online platforms such as Airbnb and HomeAway. Faced with a lack of funding for heritage conservation, the sharing economy has provided this historic residential area with new possibilities, leading to gentrification and polarisation. In many historical communities, residents who are capable of purchasing properties in other places of Shanghai and bearing the cost of renovation often choose gentrification as a way of furthering their economic interests (Williams and Arkaraprasertkul 2017). ${ }^{20}$ However, in Bugaoli, such change is not welcomed by many elderly people, who live life even more slowly than other residents. The elderly are the residents who most appreciate the memories and culture of their small society. The openness and easy access to information through the internet have an immediate impact on urban areas regardless of geographic location, language, culture or ethnicity. In this respect, small businesses have infiltrated and sped up the temporality governing the economy in Bugaoli.

The cultural image and economic prosperity that the Shanghai municipality has aimed to create conflict with the low rental prices that residents have paid for generations. Globalisation, in particular, has had a profound impact on the formation of urban landscapes and urban heritage practices. Considering both municipal engineering construction for safety standards and the sharing economy for tourist consumption as examples, the leading actors in those economic activities were not directly connected to the Bugaoli community. Bugaoli, as a listed heritage site, is both beneficiary and victim of globalisation. These actions to enhance the quality of Bugaoli and attract investment and tourists were strategies formulated by outside stakeholders functioning in shortterm economic time, while the legislative framework restrains and guides development by means of laws and regulations over the long term. Although the CRPS has 
evolved more slowly than economic development in the globalised urban landscape of Shanghai, this system provides a buffer against radical intervention in Bugaoli and other urban heritage sites. At the same time, struggling with its legislative and citizen times, there was little apparent economic progress in Bugaoli community while many neighbourhoods adjacent to it have gained considerably from economic expansion. A contradiction exists between development and conservation in urban heritage sites that are also residential areas important in people's everyday lives.

\section{Citizen time: spatial continuity and dynamic community identities in Bugaoli}

Citizen time, that is, time in everyday life plays an important role in the conservation of Bugaoli. It is based on long-term interaction and the slow construction of networks, families, and identities. Changes in the composition of the population and in social networks over time have an important impact on the ways in which inhabitants preserve the area, appreciate its history and advocate for change. This study suggests that different temporalities have created divisions between old and young people, long-term and short-term inhabitants, and between local Shanghainese and outsiders. In the process of Bugaoli's urban change, three characteristics of citizen time are particularly relevant: a sense of community as well as individual attachment, the entitlement created by the colonial past, and a sense of a temporary living shelter. First, the citizens' sense of community is weakening as a result of demographic changes. In the context of expanding urbanisation in Shanghai, the individual sense of belonging to Bugaoli has also become vulnerable. Second, supported by the landmark designation, residents have constructed the image of a beautiful and hygienic community protected by its heritage status, yet without any substantial renovation. Third, Bugaoli residents see their settlement as serving urban society in diverse ways, such as offering temporary shelter to refugees during the colonial period as well to migrants today. The settlement's residents hold a diverse and often contradictory set of images and perspectives.

Communities and social networks change over time and are dependent on the community's support for communal space. The lilong neighbourhood and its gated and hierarchically organised urban texture offer a

\footnotetext{
${ }^{21}$ The term chaxugeju is used to describe the relationship among individuals rather than different social classes. It is also a social structure of grade connected by guanxi (关系), the fundamental driving force in personalised social networks of Chinese culture.

${ }^{22}$ This interview was conducted in 2018 by Kaiyi Zhu in Bugaoli community.

${ }^{23}$ Ibid.

${ }^{24}$ Ibid.
}

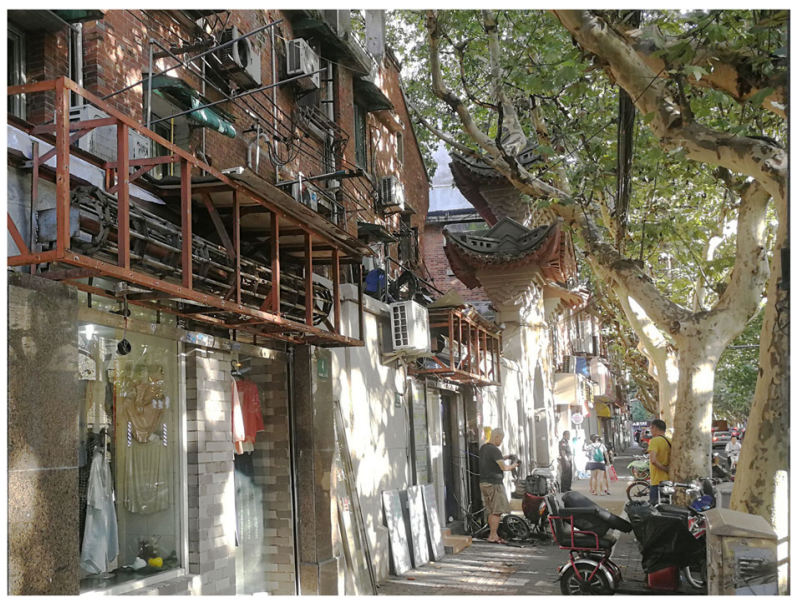

Fig. 9 The façade of Bugaoli facing the South Shaanxi Road, presenting no physical protection of this historic environemnt, its orginal components or its aesthetic values (Source: Kaiyi Zhu, 2018)

relatively internal private living environment amid the city (Bracken 2013). Families in Bugaoli and other historic communities once lived close together, and everyday activities took place on an intimate scale, which created the social relationships typical of traditional vernacular communities once often found in rural China. Fei et al. (1992) names this social network as chaxugeju (差序格局), a relationship formed by every individual rather than different social classes. ${ }^{21}$ Since the 1980s, the gradual departure of Bugaoli's original population has weakened or destroyed the close relationship once shared by neighbours. As a result, the communal space that needs to be safeguarded by local inhabitants appears neglected. One interviewee complained, 'An increasing number of battery-powered motorcycles are occupying our shared alleys, which were semi-public space for children's play and gatherings for the grown-ups. ${ }^{, 22}$ The people who can share their collective memories and sense of belonging have left, and the semi-public places, which can bridge the community and enhance their emotional interaction, have vanished.

The changes in household size and population density reflect the loss of Bugaoli's social network. Traditionally, these social networks allowed for the urban conservation of community structures and everyday life. In 2018 interviews, several senior residents said, 'We as long-term residents usually are careful about keeping our living space clean and tidy, but unfortunately, we cannot persuade the others to cooperate. ${ }^{23}$ One resident said, 'Some small retailers made our streets dirty, and besides, they even threatened and tried to hit us when we complained. ${ }^{, 24}$

\footnotetext{
${ }^{25}$ This so-called hukou system was established in 1958 and intended to legally identify each citizen's household registration by recording their births, deaths, marriages, and household moves.
} 
Such statements demonstrate the precarity of the sense of community in Bugaoli. The spirit of a cooperative neighbourhood in which residents build a close relationship is no longer the norm. The decline of social networks in recent years has led to the disappearance of a social order in which people take care of communal space.

The spaces of Bugaoli that were originally conceived for middle-class families in the 1930s are not in line with the needs of contemporary households and lifestyles. This has led to requests for architectural transformation. Local inhabitants have made changes, adding stainless steel doors and windows for theft prevention and window canopies for shade. There are also white plastic sewage pipes exposed to the architectural façade and cables installed by the local government. These interventions are necessary for modern living and can partially be justified even under the CRPS, in terms of financial benefits, living standards, privacy and security. However, small retailers in the apartments facing public streets have made numerous incongruous changes as well. Some retailers painted the traditional rusty-red iron window fences that echo the red bricks of the facades in a non-traditional light green colour. They also added street billboards and glass display windows (Fig. 9). Those alterations conceal the original architectural features of Bugaoli and violate the original aesthetics. If alterations do not fit the original aesthetic system of the neighbourhood, they should be forbidden by the regulations of a more carefully considered CRPS.

The length of residents' residence in the neighbourhood to some extent determines their attitudes towards Bugaoli and, whether they treat it as 'home' or a 'shelter'. The length of stay has also affected residents' awareness of urban conservation as a result of its concrete financial implications. Shanghai's household registration in Bugaoli occurred before the arrival of the commodity economy. Benefiting from the welfare-oriented public housing distribution system in the 1950s and 1960s, most senior residents and their younger generations pay extremely low rent, especially considering the lilong housing is centrally located with convenient transportation and services. For multiple historical reasons, the rental price has not changed for many decades. With housing commercialisation and the rise of the real estate market in China, the hukou system plays a significant role in China's big cities, with far-reaching effects on Bugaoli. ${ }^{25}$ The average rental price paid by the long-time residents in Bugaoli is only equal to $1 \%$ or even less than the rent paid by newcomers. The inhabitants who are benefiting from such privilege are most often the

\footnotetext{
${ }^{26}$ This interview was conducted in 2018 by Kaiyi Zhu in Bugaoli community.

${ }^{27}$ Ibid.
}

residents who regard Bugaoli as 'home' and who would like to maintain or even restore the unique character of their community.

Bugaoli's history and colonial heritage are viewed differently by the various types of residents. For example, the ancestors of the residents who have lived in Bugaoli since birth usually moved into Bugaoli in the 1930s to avoid the violence and social chaos caused by war and economic crisis. These families, who moved to Bugaoli before 1949, passed down their lilong housing from one generation to another along with continuity and a strong sense of place. These citizens have a neutral attitude towards the semi-colonial treaty period. They feel that the buildings in the foreign settlements sheltered them during the Sino-Japanese War and that they have been preserved. Mr Zhou, who is in his 70s, narrated his family's story: 'When my grandparents knew the Japanese army would enter Shanghai, they took the whole family and moved from the old town to the French Concession; from then on, our family settled down here. ${ }^{26}$ This group supports urban conservation both in terms of spatial structures and the community lifestyle. Another residential group who moved to Bugaoli during Shanghai's industrial development from the 1950s through the 1960 s and the 1970 s, when cross-city population movements frequently occurred due to welfare housing allocation opportunities or marriage, has a certain attachment to the place. However, a considerable number of people in this group do not fully support the conservation of their living area and see the Bugaoli community as 'a result produced by foreigners' ${ }^{27}$ Many residents argued in interviews that the cultural values of the area were overstated. They displayed a more tolerant attitude to the natural demise of lilong housing and preferred it to be demolished rather than protected.

By focusing on the long-term collective memory of Bugaoli, the original families formulate specific requirements for conservation and blame the area's decay on the government's inaction and the inequality of the global economy. Interviewee Mr Yang stated that it is not the local residents' responsibility to conserve urban heritage sites like Bugaoli and improve their condition. He complained about several aspects of the current situation. He blamed the local government for not completely recognising the importance of cultural conservation. He felt the local government lacked an understanding of the traditional way of life in lilong communities and the need to adjust the space for daily necessities. He also expressed the opinion that for local residents like himself, it is necessary to select various lilong apartments and revert architectural styles and scenes to the look of each historical period in the past as 
a museum-type environment. For the rest of the lilong housing in Bugaoli, he called for thorough maintenance and transformation, funded by the government. Mr Yang thought that the flaws in the legislative framework made the local residents unable to reliably communicate with authorities and decision-makers. In the process of delivering needs or suggestions from the community to government agencies, the inefficiency of the bureaucratic hierarchies and verbose processes creates a morass of misinformation and communication blockages. ${ }^{28}$ This impedes both conservation and renovation that would be compatible with the cultural richness and diversity of Bugaoli's identity.

Mr Yang is an example of a large number of seniors who have strong emotional ties to Bugaoli and many memories. While awaiting government action, many elderly inhabitants have lost the will and ability to master the rules and monitor the process to improve their living environment. They have gradually become opposed to the imposition of legislative time and economic time in Bugaoli. They also fail to communicate and cooperate with actors operating on those temporal levels. Yet, too much focus on historic citizen time can lead to unrealistic expectations. Residents' views of Bugaoli are limited to a small neighbourhood scale. They largely ignore the transformation of surrounding areas and the legal changes and economic transformation occurring in the rest of the city, especially the economic boom of the decade following the Shanghai 2010 Expo. When inhabitants criticise the government and capitalism in an emotional tone, they limit their ability to cooperate and contribute to the CRPS.

\section{Conclusion}

Situated in flourishing old Shanghai, the lilong settlements have experienced Shanghai's urbanisation throughout the 20th and 21st century. The dynamic identity of this modern residential heritage is reflected in sometimes overlapping, sometimes conflicting, legislative, economic and citizen temporalities. In its legislative and legal time, the listed status of Bugaoli demonstrates Shanghai's inclusive vision of an international heritage discourse for China. Regarding economic temporality, Bugaoli has been made into an emblem of Shanghai for the tourist industry and used as an example of municipal infrastructure projects that serve the city's modern makeover. Its citizen time is characterised by the contradictory sense of community that persists in families, networks, residents' incomes and their connection with the colonial past. Citizen time, encompassing identity formed by group characters and collective memories, presents the sense of 'community' the most. In urban heritage conservation, in particular community conservation, emphasis on citizen time helps to enhance the concern for reality in the heritage process rather than political ideologies or economic goals. When legislative, economic and citizen temporalities of Bugaoli are not aligned, the result may be a collision of objectives for the community's future.

Multiple temporal regimes have been in competition with each other, creating inequality in urban heritage areas. In the 21st century, economic time suppressed other temporalities in Shanghai in urban heritage practice. Shanghai's economic goal of branding lilong housing for the city's tourism industry helped attract attention to prominent historic lilong districts like Bugaoli at the time of the 2010 EXPO. Since then, economic time gradually prevailed over other temporal regimes in historic districts. Bugaoli, frozen in the status under the guidelines of the CRPS, has been facing its decline with a sense of powerlessness. As long-term residents are getting older, with most over 70 years old, the sense of 'community' evoked since the 1970s in urban conservation discourse is vanishing.

This paper emphasises David Lowenthal's (1985) understanding of history and heritage, which is dynamic and always a process. Considering the future, this paper suggests that the phenomenon of ageing taking place in many historic neighbourhoods needs to be addressed in order to preserve collective memories for the next generation. Some urban elements, such as transport facilities, landmark buildings and public space, can evolve more quickly and keep up with the changes in the urban landscape brought about by globalisation and capitalisation, but some elements need more time to adapt in order to meet internal demands. This study of temporalities in Bugaoli challenges analyses of urban heritage conservation that focus only on changes in space and architectural forms of historic areas in a single time dimension while ignoring the dynamic nature of history and the plurality of time.

In Shanghai, the dilemma of urban community conservation lies not in what values have more weight but which heritage approaches can enrich and sustain both the tangible and intangible significance of a historic neighbourhood like Bugaoli. It is necessary to recognise the dynamic nature of urban heritage as it has evolved together with social development and the evolution of actual practices (Schoorl 2005). Bugaoli was built by foreign forces but has been appreciated by local residents, in a way that challenges a general heritage discourse authorised by Western white elites. The dynamic nature of lived heritage communities requires heritage strategies that balance legal norms, economic interests and the needs of citizens. Apart from problems accumulated over time, including architectural deterioration and housing rent imbalances, it is necessary to clarify the values and significance of Bugaoli in terms of the city's 
economic policies and cultural identity. The listed status under the CRPS endows Bugaoli with an overarching baseline for practical activities that may occur within. Actors in each of the different temporal frameworks-legislative, economic and citizen-can influence the future of Bugaoli as a preserved residential heritage community. To do so effectively requires the careful establishment of networks and in-depth consultation, ensuring an inner order and continuity in urban heritage and its relationship with other parts of a city. This can be done in the context of the shifting dynamics of legislative, economic and citizen temporalities.

\section{Acknowledgements}

This work is supported by the China Scholarship Council and Chair History of Architecture and Urban Planning, Delft University of Technology.

\section{Authors' contributions}

Kaiyi Zhu undertook the field research, interviews and researched the background information of China's heritage studies. Carola Hein proposed the temporalities framework and helped with its implementation in the text and the analysis of the findings. The manuscript emerged as a back and forth between the authors with support from Rosemary Wakeman, several anonymous reviewers and the Built Heritage editorial team. All authors read and approved the final manuscript prior to publishing.

\section{Funding}

Not applicable.

\section{Availability of data and materials}

Not applicable.

\section{Competing interests}

Not applicable.

Received: 26 July 2020 Accepted: 29 July 2020

Published online: 20 August 2020

\section{References}

Ahmad, Yahaya. 2006. The scope and definitions of heritage: From tangible to intangible. International Journal of Heritage Studies 12 (3): 292-300.

Benjamin, Walter, and Howard Eiland. 2003. The arcades project. Cambridge: The Belknap Press of Harvard University Press. https://www.worldcat.org/title/ arcades-project/oclc/718268066\&xreferer=brief_results.

Bonfiglioli, Sandra, and Xiaojing Ma. 2010. "Chengshi fazhan de shijian yanjiu: Yidali shi de chuangxin." [Time Studies in Urban Development: An Italian Innovation.] Urban Planning International, no. 3: 21-26.

Bracken, Gregory. 2013. The Shanghai alleyway house. A vanishing urban vernacular. London: Routledge. https://www.worldcat.org/title/shanghaialleyway-house-a-vanishing-urban-vernacular/oclc/930811012\&referer=brief_ results

Butler, Tim. 2007. For gentrification? Environment and Planning A 39 (1): 162-181.

Canziani, Andrea. 2008. Being and Becoming of Modern Heritage. In The Challenge of Change Dealing with the Legacy of the Modern

Movement-Proceedings of the 10th International Docomomo Conference, ed. D. Van Den Heuvel, M. Mesman, W. Quist, and B. Lemmens, 5-10. Amsterdam: IOS Press.

Champion, Matthew S. 2019. The history of temporalities: An introduction. Past \& Present 243 (1): 247-254

Chang, Qing. 2009. "Jiugai zhong de Shanghai jianzhu jiai dushi lishi yujing." [Shanghai Buildings Remodeled in Old District and the Metropolitan Historical Discourse Context] Architectural Journal, no. 10: 23-28.

Chang, Qing. 2019. Architectural models and their contexts in China's 20thcentury architectural heritage: An overview. Built Heritage 3 (4): 1-13.

Cheng, Zai, and Jianxi Wu, eds. 2016. Lao Shanghai baiye zhinan: Daolu jigou changshang zhuzhai fenbu tu [guide of old Shanghai's industries: Distribution of roads, institutions, factories, business and houses]. Shanghai: Shanghai Academy of Social Science Press.
Fei, Xiaotong, Gary G. Hamilton, and Zheng Wang. 1992. From the soil: The foundations of Chinese society. Berkeley: University of California Press.

Greer, Shelley, Rodney Harrison, and Susan Mclntyre-Tamwoy. 2002. Communitybased archaeology in Australia. World Archaeology 34 (2): 265-287.

Hargrove, Cheryl. 2017. Cultural heritage tourism: Five steps for success and sustainability. Lanham: Rowman \& Littlefield.

Harrison, Rodney. 2013. Forgetting to remember, remembering to forget: Late modern heritage practices, sustainability and the 'crisis' of accumulation of the past. International Journal of Heritage Studies 19 (6): 579-595.

Harvey, David. 2005. Spaces of Neoliberalization: Towards a theory of uneven geographical development. Stuttgart: Franz Steiner Verlag.

Harvey, David C. 2001. Heritage pasts and heritage presents: Temporality, meaning and the scope of heritage studies. International Journal of Heritage Studies 7 (4): 319-338.

Henckel, Dietrich, and Thomaier Susanne. 2013. Efficiency, temporal justice, and the rhythm of cities. In Space-time Design of the Public City, ed. Dietrich Henckel, Susanne Thomaier, Benjamin Könecke, Roberto Zedda, and Stefano Stabilini, 99-117. Dordrecht: Springer.

ICOMOS. 1987. "Charter for the Conservation of Historic Towns and Urban Areas Washington Charter." ICOMOS. https://www.icomos.org/en/what-we-do/ focus/179-articlesen-francais/ressources/charters-and-standards/159-charterfor-the-conservation-of-historic-towns-and-urban-areas. Accessed 19 July 2020.

Jokilehto, Jukka. 2007. International charters on urban conservation: Some thoughts on the principles expressed in current international doctrine. City \& Time 3 (3): 2

Kaminski, Jaime, Angela M. Benson, and David O. Arnold. 2017. Contemporary issues in cultural heritage tourism. London: Routledge.

Kohl, Jonathan, Stephen McCool, and Sam Ham. 2016. The future has other plans: Planning holistically to conserve natural and cultural heritage. Golden: Fulcrum Publishing.

Lowenthal, David. 1985. The past is a foreign country. Cambridge: Cambridge University Press.

Lowenthal, David, and Marcus Binney. 1981. Our past before us: Why do we save it? London: Temple Smith

Lu, Yongyi, and Yanning Li. 2019. Defining local heritages in preserving modern Shanghai architecture. Built Heritage 3 (3): 3-20.

Martokusumo, Widjaja. 2002. "Urban heritage conservation." The Indonesian Town Revisited no. 1: 374

Sassen, Saskia. 2000. Spatialities and temporalities of the global: Elements for a theorization. Public Culture 12 (1): 215-232

Schoorl, Fred F.J. 2005. On authenticity and artificiality in heritage policies in the Netherlands. Museum International 57 (3): 79-85.

Shen, Hua. 1993. Shanghai lilong minju [Shanghai Lilong Housing]. Beijing: China Architecture \& Building Press.

Smith, Laurajane. 2006. Uses of heritage. London: Routledge.

State Council. 2017. "Cultural Relics Protection Law of the People's Republic of China." Accessed 19 July 2020. http://www.scio.gov.cn/xwfbh/xwbfbh/ wafbh/37601/38374/xgzc38380/Document/1630060/1630060.htm

UNESCO. 1976. "Recommendation Concerning the Safeguarding and Contemporary Role of Historic Areas." http://portal.unesco.org/en/ev.phpURL_ID=13133\%26URL_DO=DO_TOPIC\%26URL_SECTION=201.html. Accessed 19 July 2020

Vecco, Marilena. 2010. A definition of cultural heritage: From the tangible to the intangible. Journal of Cultural Heritage 11 (3): 321-324

Waterton, Emma, and Laurajane Smith. 2010. The recognition and misrecognition of community heritage. International Journal of Heritage Studies 16 (1-2): 4-15.

West-Pavlov, Russell. 2012. Temporalities. London: Routledge.

Williams, Matthew, and Non Arkaraprasertkul. 2017. Mobility in a Global City: Making sense of Shanghai's growing automobile-dominated transport culture. Urban Studies 54 (10): 2232-2248.

Wu, Fulong. 2000. The global and local dimensions of place-making: Remaking Shanghai as a World City. Urban Studies 37 (8): 1359-1377.

Yang, You-Ren, and Chih-hui Chang. 2007. An urban regeneration regime in China: A case study of urban redevelopment in Shanghai's Taipingqiao area. Urban Studies 44 (9): 1809-1826.

Zhang, Song. 2006. "Shanghai chengshi yichan de baohu celve." [Conservation Strategy of Urban Heritage in Shanghai.]. City Planning Review 30 (2): 49-54. 
Zhong, Xiaohua, and Xiangming Chen. 2017. Demolition, rehabilitation, and conservation: Heritage in Shanghai's urban regeneration, 1990-2015. Journal of Architecture and Urbanism 41 (2): 82-91.

Zhu, Xiaoming, and Donghai Zhu. 2012. Bogendi zhi cheng: Shanghai lao longtang shenghuo kongjian tujing [Cité Bourgogne: A historical picture of living Sapce in Shanghai old alley]. Beijing: China Architecture \& Building Press.

\section{Publisher's Note}

Springer Nature remains neutral with regard to jurisdictional claims in published maps and institutional affiliations.

Submit your manuscript to a SpringerOpen ${ }^{\mathcal{O}}$ journal and benefit from:

- Convenient online submission

- Rigorous peer review

- Open access: articles freely available online

- High visibility within the field

- Retaining the copyright to your article

Submit your next manuscript at $\boldsymbol{\wedge}$ springeropen.com 